\title{
Circulatory and Respiratory Responses to Medullary Stimulation in the Dog
}

\author{
Hideo Ueda, M.D., * Akio Kurorwa, M.D., Hitoshi Goto, M.D., \\ Iwao Iтo, M.D., Kiyoshi Ito, M.D., and Soichi Katayama, M.D.
}

Electrical stimulation in medulla oblongata has been carried out in 36 dogs with the purpose of studying the mechanism of cardiovascular and respiratory regulation. By electrocardiographic registration, changes in heart beats were examined, and disturbances of heart rate and rhythm were suggested to be due to direct vagal nucleus stimulation or due to vagal reflex by arterial pressure change. Blood pressure elevation occurred often together with bradycardia. This seemed in part due to baroceptor reflex, but in other part due to primary cardioinhibitory effect. These mechanisms were discussed.

$\mathbf{T}$

HE function of the medulla oblongata has been investigated by many authors since Dittmar's exploration (1870), especially about the cardiovascular and respiratory regulation. Ranson and Billingsley ${ }^{1)}$ explored the floor of the fourth ventricle with a needle electrode and found 2 discrete reaction points or small areas. From one of these, rises in arterial pressure were consistently obtained, while the other yielded depressor responses. On the respiratory function, Miller ${ }^{2)}$ reported the respiratory change by stimulation of the floor of the fourth ventricle. These works were followed by a number of similar explorations. Wang and Ranson, ${ }^{3)}$ Pitts $^{4}$ Alexander, ${ }^{5)}$ Bach, $^{6)}$ and Yamamoto ${ }^{7)}$ made the mappings of pressor and depressor points, and the expiratory and inspiratory points in the cats.

But the change of the heart rate was scarcely investigated by previous studies. For this reason, the following experiments were designed to examine the effect on the heart rhythm, simultaneously on the changes of blood pressure and respiration with stimulating electrode.

\section{MEthod}

Mongrel dogs weighing 8 to $15 \mathrm{Kg}$. were anesthetized with morphine chloride (3mg. $/ \mathrm{Kg})$ and chloralose $(50 \sim 70 \mathrm{mg} . / \mathrm{Kg})$. With the aid of the stereotaxic instrument devised by the Institute of Brain Research, Faculty of Medicine,

From the Second Department of Internal Medicine, Faculty of Medicine, University of Tokyo, Tokyo.

* Professor of Internal Medicine. 
University of Tokyo, the stimulating electrode was placed in the bulbar regions. The location of the tip of this electrode was determined by histological control following each experiment. The electrical stimuli were generally 2 to 10 volts, 1 millisecond in duration, and 30 to 100 rectangular pulses per second in frequency. These stimuli were introduced about 15 to 30 seconds. The blood pressure was recorded from the femoral artery using a mercury manometer. Electrocardiogram was taken on the standard limb lead and the intraatrial lead. The respiratory movement of the thorax was registered by means of a tambour connected to the cuff wrapping around the thorax, or a transducer of rubber tube filled with zinc sulfate solution.

\section{RESUlts}

Two hunded and ninety-six stimuli in 105 points in the medulla were explored. Circulatory and respiratory responses obtained by these stimuli are shown in Fig. 1 and Table I, II.
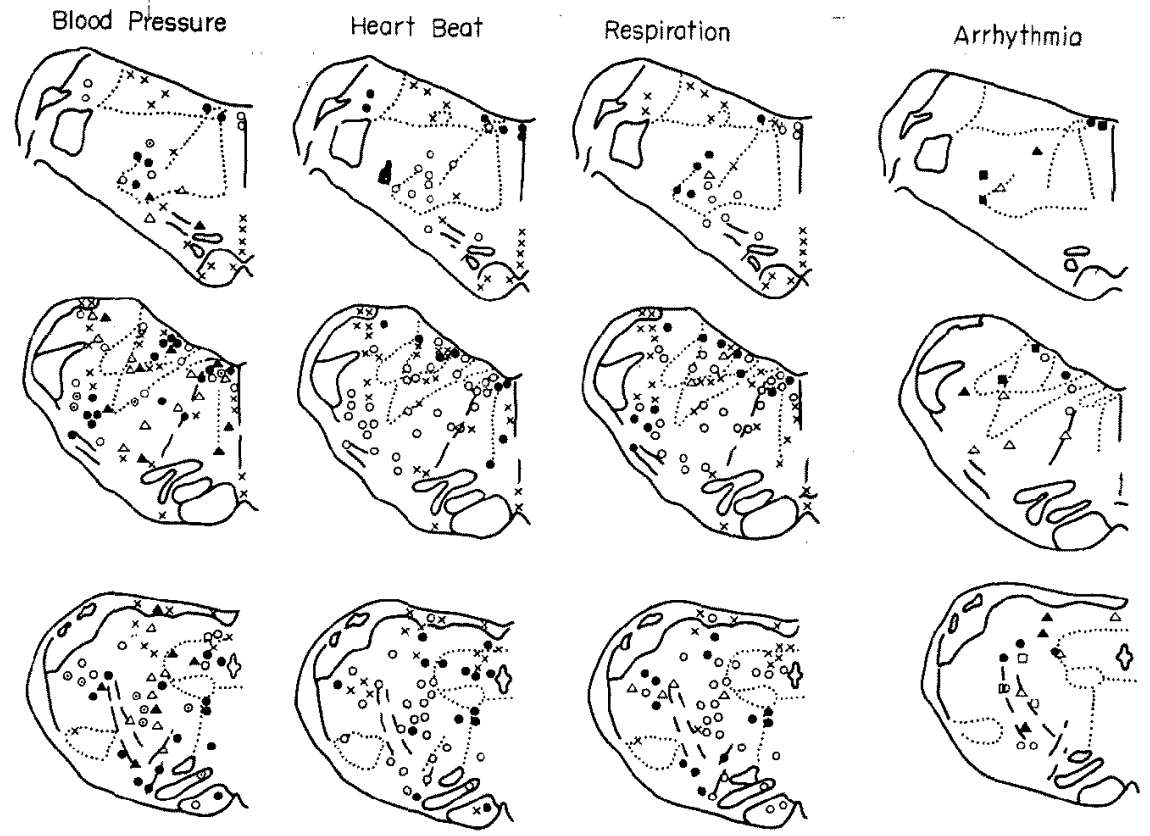

- Marked elevation

- Tochycardia

- Moderate

$\times$ No change

- Slight

$\times$ No change

- Bradycardia

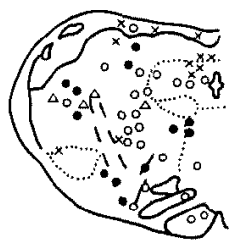

- Expiratoric apnea

- Inspiratoric apnea

$\Delta$ Intermediate

$x$ No chonge

- Auricular fibrillation

- Ectopic tachycardia

$\triangle$ Ventricular extrasystole

- Marked

A-V block

- Nodal rhythm

- Sinus arrest

Fig. 1. Changes in blood pressure, heart beat and respiration by medullary stimulation. 
Table I. Incidence of Various Arrhythmias and Other Changes in Vagal Nuclei and Other Parts

\begin{tabular}{|c|c|c|c|c|c|c|}
\hline & $\begin{array}{l}\text { Exp. } \\
\text { No. }\end{array}$ & \multicolumn{3}{|c|}{$\uparrow^{\text {Blood Pressure }} \uparrow \downarrow$} & Heart Rate & Respiration \\
\hline $\begin{array}{l}\text { Nucl. dorsalis n. } \\
\text { vagi }\end{array}$ & 19 & 11 & 4 & 3 & 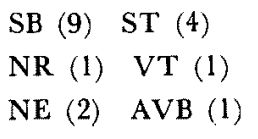 & Insp. Exp. \\
\hline Nucl. ambiguus & 19 & 3 & 11 & & $\begin{array}{l}\mathrm{SB}(13) \quad \mathrm{NR}(4) \\
\mathrm{VE}(3) \quad \mathrm{AF}(1)\end{array}$ & Exp. \\
\hline Nucl. solitarius & 22 & 13 & 3 & 4 & $\begin{array}{l}\mathrm{SB}(18) \quad \mathrm{AVB}(2) \\
\mathrm{NR}(3) \\
\mathrm{VA} \\
\mathrm{SA}(1) \\
\mathrm{AF}(1)\end{array}$ & Insp. \\
\hline Nucl. intercalatus & 19 & 9 & 3 & 7 & $\begin{array}{l}\mathrm{SB}(13) \quad \mathrm{AVB}(8) \\
\mathrm{VE}(5)\end{array}$ & Insp. Exp. \\
\hline Subst. gellat inosum & 18 & 10 & 5 & & $\begin{array}{l}\mathrm{SB}(12) \quad \mathrm{NE}(3) \\
\mathrm{NR}(1)\end{array}$ & Insp. \\
\hline
\end{tabular}

SB: sinus bradycardia, ST: sinus tachycardia, VE: ventricular extrasystole, VT: ventricular tachycardia, NR: nodal rhythm, NE: nodal extrasystole or escaped beat, AF: atrial fibrillation, SA: sinus arrest, Insp: inspiratoric apnea, Exp: expiratoric apnea

Table II. Response in Reticular Formation

\begin{tabular}{|c|c|c|c|c|}
\hline & & Blood Pressure & Heart Rate & Respiration \\
\hline \multirow{5}{*}{ Rostral } & Dorsal & $+\sim H$ & ST & Exp. \\
\hline & Ventral & - & SB & Insp. \\
\hline & Medial & $?$ & $?$ & Insp. \\
\hline & Lateral & $+\sim H$ & ST & Exp. \\
\hline & Central & $H \sim H$ & SB & $?$ \\
\hline \multirow{5}{*}{ Middle } & Dorsal & $-\sim m$ & $\mathrm{ST}$ & Exp. \\
\hline & Ventral & - & $\mathrm{SB}$ & Insp. \\
\hline & Medial & - & ST & Insp. \\
\hline & Lateral & $+\sim \#$ & SB & Exp. \\
\hline & Central & - & SB & Insp. \\
\hline \multirow{5}{*}{ Caudal } & Dorsal & - & $\mathrm{ST}$ & Exp. \\
\hline & Ventral & $-\sim H$ & SB & Insp. Exp. \\
\hline & Medial & $H \sim H$ & $\mathrm{ST}, \mathrm{SB}$ & Exp. \\
\hline & Lateral & $+\sim m$ & SB & Exp. \\
\hline & Central & - & SB & Exp. \\
\hline
\end{tabular}

$\mathrm{O}$ : no change, + : slight elevation, $H$ : moderate elevation, H: marked elevation, -: fall, ST : sinus tachycardia, SB : sinus bradycardia. Insp: inspiratoric apnea, Exp: expiratoric apnea. 
The blood pressure response: The changes of blood pressure are divided into 5 degrees; marked elevation (over 50\% increase), moderate elevation $(20 \sim 50 \%)$, slight elevation $(<20 \%)$, slight fall $(<20 \%)$ and marked fall $(\geqq 20 \%)$.

Fig. 1-a shows the localization of the pressor and depressor points. The pressor response was obtained in the nucleus ambiguus, the substantia gelatinosa, the nucleus fasciculus lateralis, and in the lateral reticular formation and in the dorsal and central portions at the rostral level of the medulla, and in the medial areas at the caudal level. Especially marked pressor response was observed in the lateral reticular formation. The distribution of the depressor points were observed in the nucleus fasciculus, and in the central and medial portions at the rostral level of the reticular formation, in the ventral, central and medial portions at the middle level, and in the central and dorsal portions at the caudal level of the reticular formation.

In the dorsal vagal nucleus, the nucleus solitarius and solitary tract, the nucleus intercalatus, and the reticular formation in the dorsal portion at the middle level and in the ventral portion at the rostral level, both the pressor and depressor responses were elicited.

The biphasic response of the blood pressure, namely the depressor response at the early stage of stimulation and the pressor response at the later stage, was observed in the nucleus ambiguus, the nucleus solitarius and solitary tract, the nucleus intercalatus and a part of the reticular formation.

The convulsion had no significant influence to the cardiovascular response (Fig. 2).
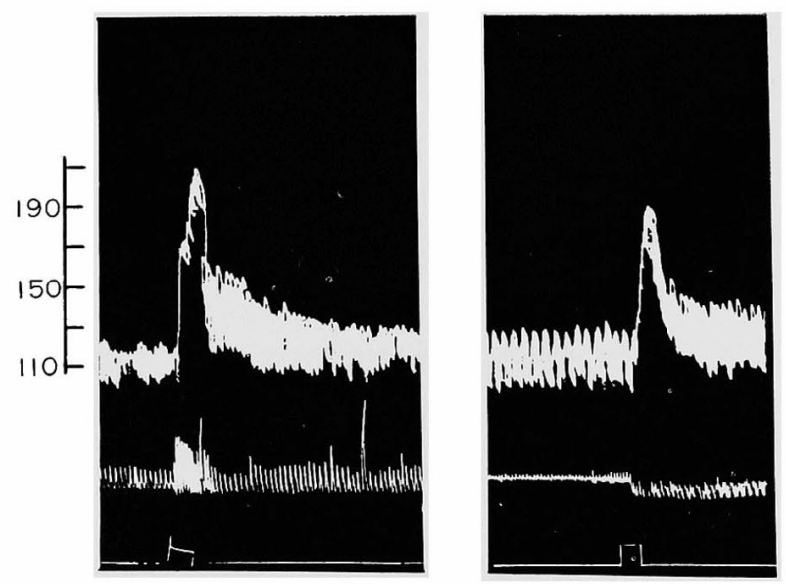

Fig. 2. Correlation in convulsion and blood pressure. a) control, b) after curarization. 
Changes in heart rate: The bradycardia response was more.often produced by medullary stimulation (Fig. 1-b, Table III). Bradycardia

Table III. Correlation between Blood Pressure and Heart Rate

\begin{tabular}{c|c|c|c|c}
\hline B.P. & Elevation & No change & Fall & Total \\
H.R. & 27 & 5 & 3 & 35 \\
Tachycardia & 25 & 69 & 17 & 111 \\
No change & 107 & 6 & 36 & 149 \\
Bradycardia & 159 & 80 & 56 & 295 \\
\hline Total & & &
\end{tabular}

occurred at the incidence of $59 \%$ of stimulation, while tachycardia was $11 \%$. The former response was observed in the nucleus ambiguus, the nucleus solitarius and solitary tract, the nucleus fasciculus, the nucleus intercalatus, and the ventral and central parts of the reticular formation and the lateral part at the middle and caudal level. The tachycardia was observed in the nucleus fasciculus lateralis, the dorsal reticular formation, the lateral portion at the rostral level and the medial portion at the middle and caudal areas. In the dorsal vagal nucleus bradycardia was usually seen, but occasionally tachycardia was also observed.

Arrhythmias were frequently observed in the various areas, especially in vagal nuclei (Fig. 1-d and Table I). In the nucleus solitarius and solitary tract the cardio-inhibitory response was notable as seen in Fig. 3
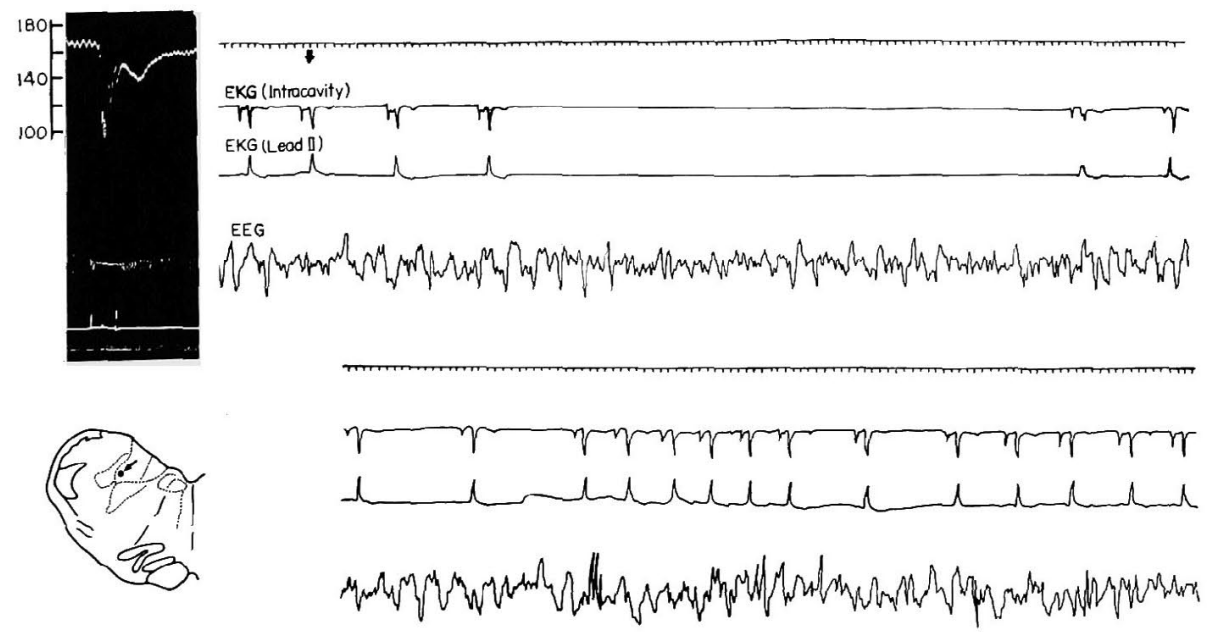

Fig. 3. Ghange by stimulation in nucleus solitarius. 
showing an example of cardiac arrest. In the nucleus ambiguus the similar response was observed. Fig. 4 represents nodal escaped beats and nodal rhythm in the early stage of stimulation, and then transient atrial

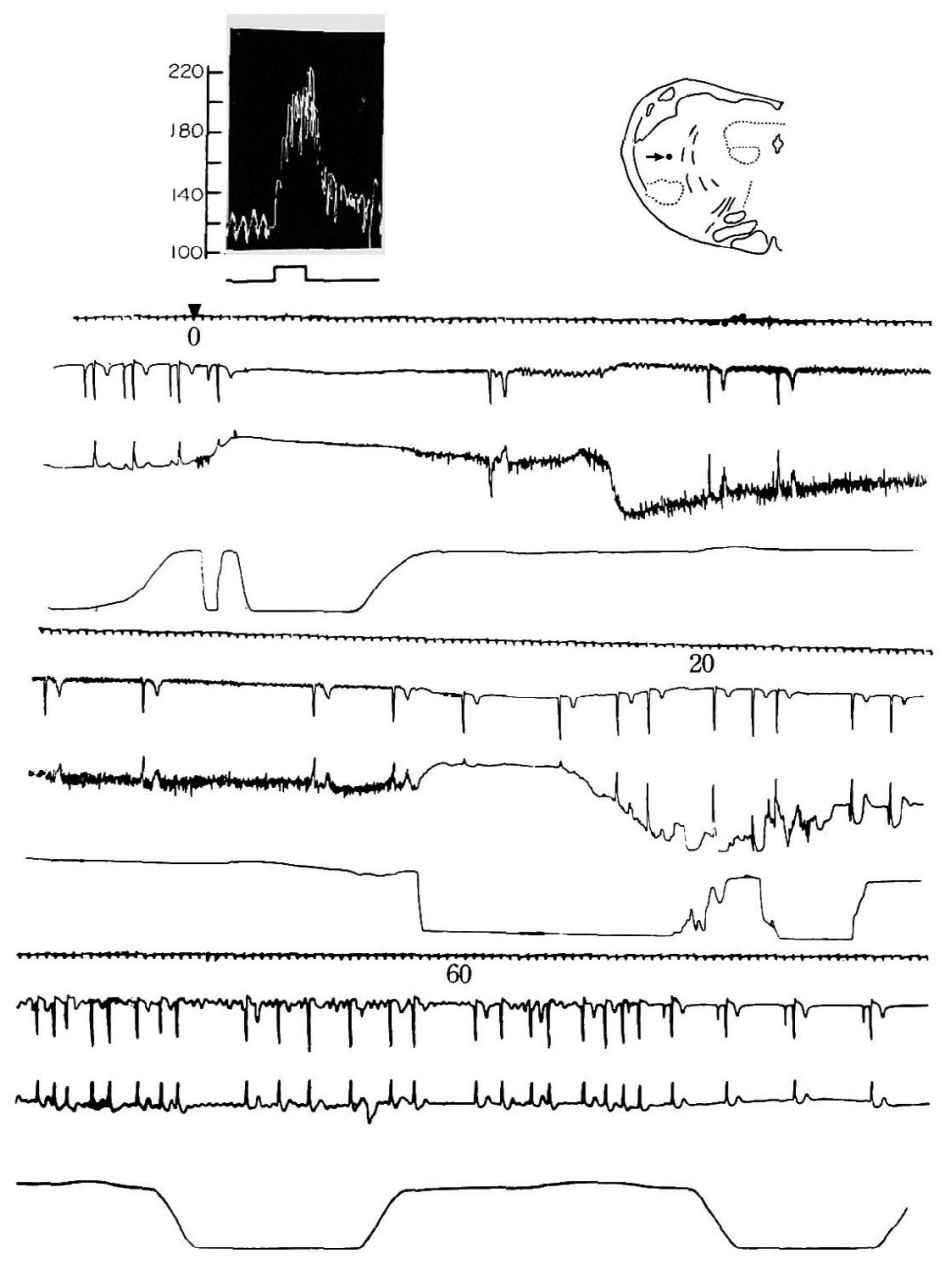

Fig. 4. Change by stimulation in nucleus ambiguus.

fibrillation occurred for about $40 \mathrm{sec}$. In the dorsal vagal nucleus cardioacceleration was sometimes seen, in some case ventricular tachycardia was elicited (Fig. 5).

Respiratory response: The respiratory response is divided into expiratory and inspiratory responses. The distribution is represented in Fig. 1-c. The expiratory response was mainly in the nucleus solitarius, the nucleus fasciculus lateralis, and the ventral and medial parts at the rostral reticular formation and the caudal central reticular formation. 

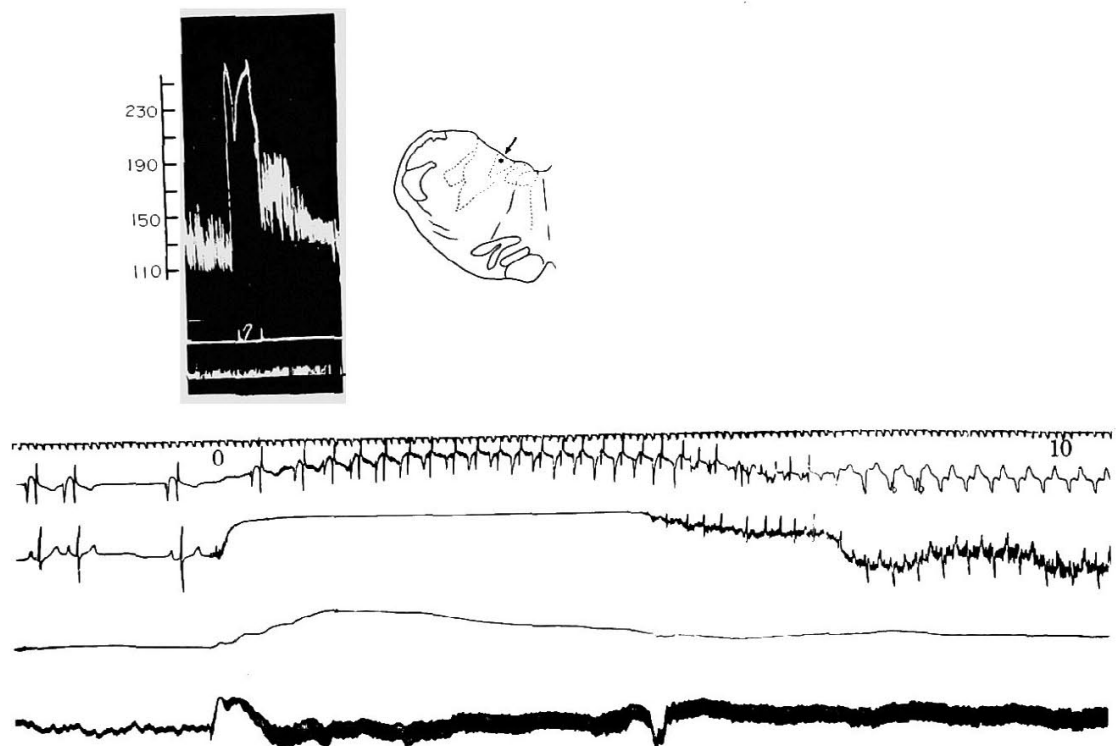

Fig. 5. Change by stimulation in dorsal vagal nucleus.

The inspiratory response was observed in the nucleus ambiguus, the dorsal vagal nucleus, and dorsal and lateral reticular formation.

No consistent correlation could be found for combinations of respiratory and arterial pressure responses.

\section{Discussion}

The distribution of the pressure response, as determined by the different authors, since Ranson et al., appears to vary much more. In regards to pressor area, Monnier ${ }^{8)}$ found in the medial central and ventral reticular formation, and Alexander showed in rostral lateral and dorsal areas. By our finding it locates in the lateral reticular formation, in the central and dorsal areas at the rostral level, and in the caudal medial part. The pressor area seen in the lateral reticular formation is in agreement with the findings of many investigators. That the pressor area also located in the central and dorsal parts at the rostral level corresponds to the findings of Wang and Bach. The localization of the pressor point in the caudal medial reticular formation is same to the observation by Bach.

The depressor area was obtained in the rostral ventral reticular formation and the central part at the middle and caudal level. This finding is in general agreement with the observation of Wang and Bach.

Thus there apprears to be general agreement that the pressor points 
are in a more rostral lateral reticular formation and the depressor points tend to occupy caudal central position.

Berry ${ }^{9)}$ reported the inversion of the pressure response with the change of frequency of stimulation, but our exploration only showed the reduction of the grade of pressure response (Fig. 6).
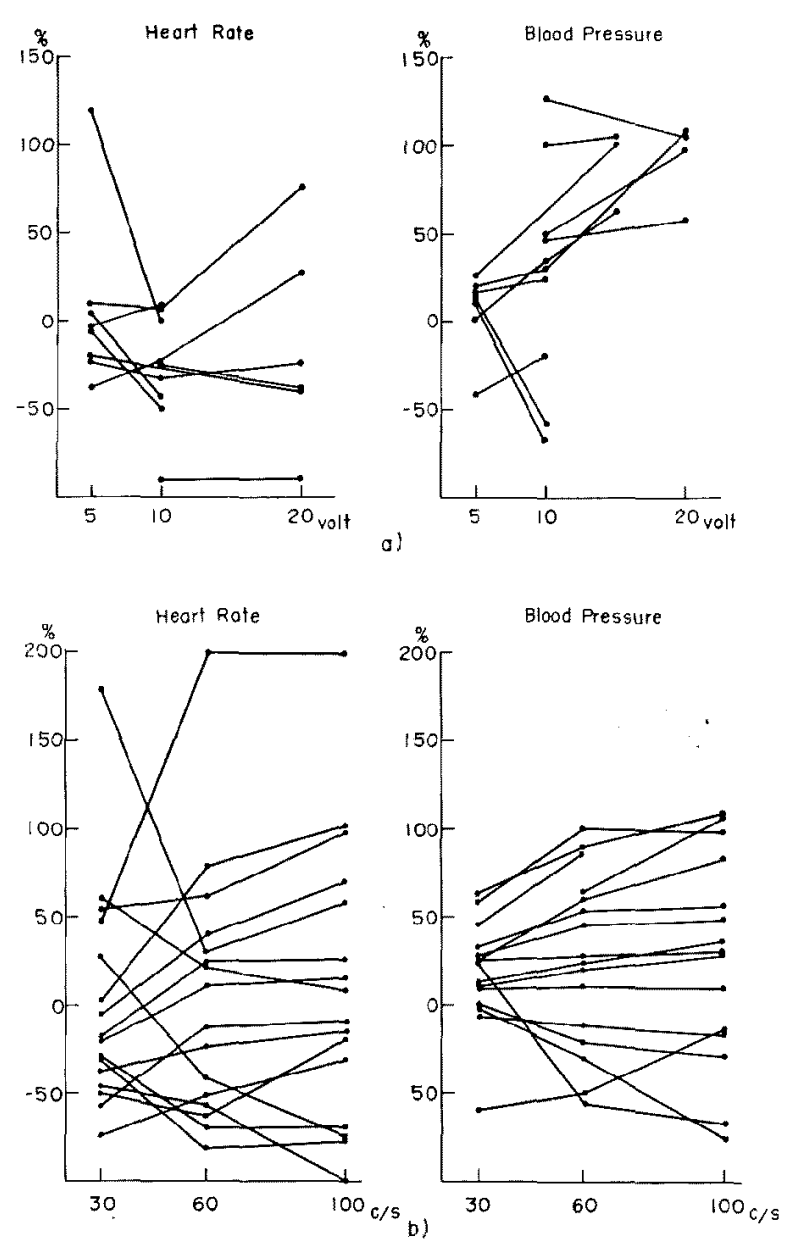

Fig. 6. Stimulating condition and feardiovascular Tresponse.

a) cardiovascular response by changing stimulating voltage.

b) by changing stimulating frequency.

There are very few experiment on the heart beat with electrocardiogram. Previous view-point ${ }^{10)}$ is that the cardioaccelerating area is confined in the pressor area in the reticular formation and the cardioinhibitory area is in the vagal nuclei or these connecting fibers. According to this opinion, the cardiovascular response must be the pressor response with 
tachycardia or the depressor response with bradycardia. However, Monnier ${ }^{11)}$ observed the pressor response with bradycardia frequently in his investigation. Our experiment also showed such cardiovascular response often (Table III). In this regard, it may be partially by a reflex, but in part this must be due to a simultaneous stimulation on the vasoconstrictor point and the cardioinhibitory point, which are suspectedly intermingled and densely packed, according to the finding that the pressor response was still observed after vagotomy (Fig. 7). On the other hand, the depressor response occurred concomitantly with bradycardia.

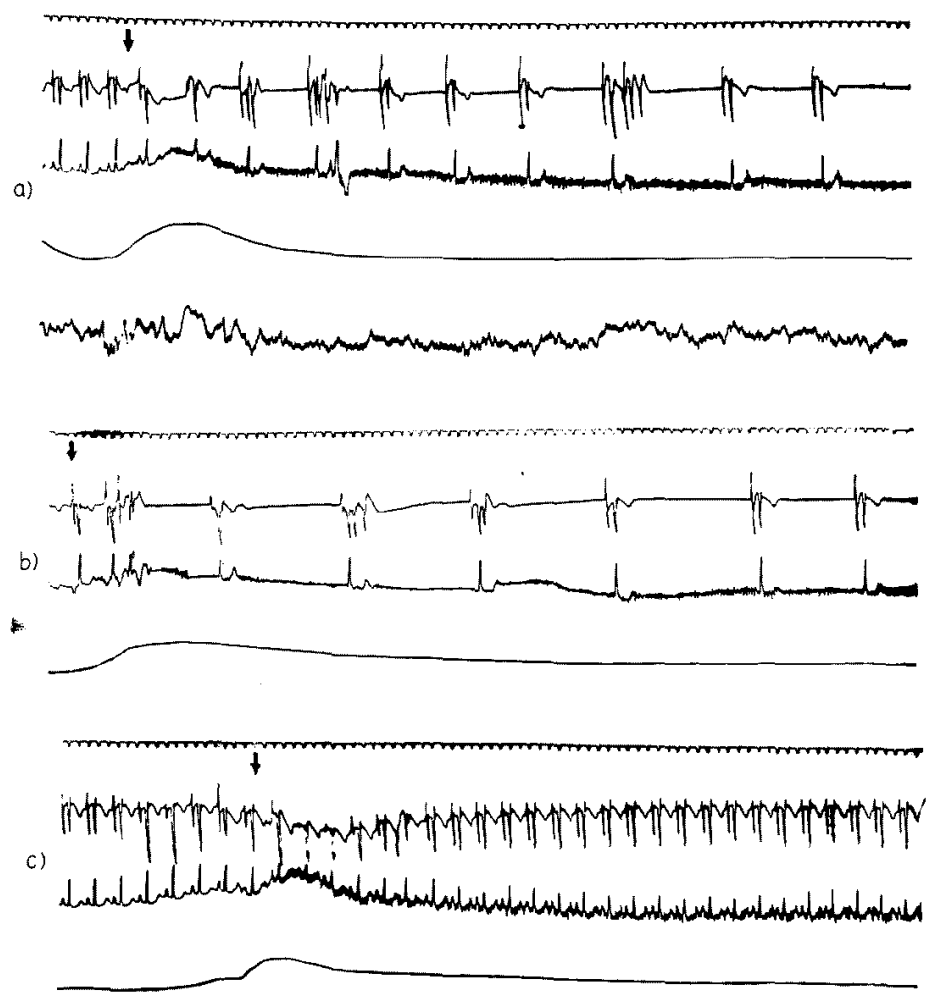

Fig. 7. Effect of cervical vagotomy on cardiovascular response.

a) control. b) after one side vagotomy. c) after both side vagotomy.

Arrhythmia induced by medullary stimulation may almost be due to the acceleration of the vagal function. But the secondary reflex by the change of systemic blood pressure may also in part be concerned.

Bronha, ${ }^{12)}$ Hodes, ${ }^{13)}$ and Kobat ${ }^{14)}$ observed a cardioaccelerating fiber in vagal rootlet, and Shizume ${ }^{15)}$ suggested its localization in the dorsal vagal nucleus. Our finding showing the cardiovascular acceleration by stimulation of the dorsal vagal nucleus seems to be in agreement with their 
histologic observation.

The mapping of the respiratory response in medulla was first drawn by Pitts. Our results are fundamentally same to Pitts, Bach, Amoroso, ${ }^{16)}$ and Ngai. ${ }^{17)}$ Although Pitts showed a discrete division between maximal expiratory part and maximal inspiratory part, other investigators showed a diffuse overlapping of both areas as our observations. Brookhart's investigation $^{18)}$ using dogs showed no discrete localization of the respiratory response.

\section{Summary}

Circulatory and respiratory changes by stimulation in the medulla oblongata were investigated in 36 dogs.

(1) The localization relating to the changes of blood pressure, heart beat and respiration was observed. The distribution of blood pressure and prespiratory response was generally in agreement with the findings of previous investigators.

(2) A fall in blood pressure was, as a rule, associated with a decrease in heart rate, and assumed to be caused by both cardioinhibitory and vasodepressor effects. Whereas, an elevation in blood pressure was occasionally associated with a decrease in heart rate. This paradoxical response seemed in part to be elicited by the reflex, but in part seemed by the direct cardioinhibitory and vasopressor effects.

(3) In dorsal vagal nucleus, the cardioinhibitory effect was obtained, but in part the cardioacceleration was also observed. This mechanism was discussed.

\section{REFERENCES}

1. Ranson, S.W., and Billingsley, P.R.: Am. J. Physiol. 41: 85, 1916.

2. Miller, F.R., and Scherrington, C.S.: Quat. J. Exper. Physiol. 9: 147, 1916.

3. Wang, S.C., and Ranson, S.W.: J. Comp. Neurol. 71: 437, 1939.

4. Pitts, R.F.: Physiol. Review 26: 609, 1946.

5. Alexander, R.S.: J. Neurophysiol. 9: 205, 1946.

6. Bach, L.M.N.: Am. J. Physiol. 171: 417, 1952.

7. Yamamoto, S.: Juzenkaishi 54: 122, 1952-3 (in Japanese).

8. Monnier, M. : Rev. Neurol. 69: 517, 1938.

9. Berry, C., McKinley., W., and Hodes, R. : Am. J. Physiol. 135: 388, 1941-2.

10. Uvnäs, B.: Handbook of physiology. Neurophysiol. II, 1131, Washington, Williams \& Wilkins, 1960.

11. Monnier, M.: Rev. Neurol. 70: 521, 1938.

12. Brouha, L., Mckinley, and Hodes, R.: J. Fhysiol. 87: 345, 1936.

13. Hodes, R.: Am. J. Physiol. 126: 171 , 1939.

14. Kobat, H.: Am. J. Physiol. 128: 246, 1940.

15. Shizume, K.: Jap. Circulat. J. 16: 8, 1952 (in Japanese).

16. Amoroso, M.C., Bell, F.R., and Rosenberg, H.: J. Physiol. 126: 86, 1954.

17. Ngai, S.H. and Wang, S.C.: J. Physiol. 190: 343, 1957.

18. Brookhart, J. M.: Am. J. Physiol. 129: 709, 1940. 